Conference Paper

\title{
The Strategy of Smart Shading System in The Residential Building at Surabaya
}

\author{
Syaifuddin Zuhri ${ }^{*}$, Imam Ghozali² ${ }^{2}$ Karina Firdauzy ${ }^{3}$ \\ ${ }^{1}$ Architecture, Architecture and Design Faculty, Universitas Pembangunan Nasional “Veteran” Jawa Timur, \\ Indonesia \\ 2Environmental Engineering, Engineering Faculty, Universitas Pembangunan Nasional “Veteran” \\ Jawa Timur, Indonesia \\ ${ }^{3}$ Information of Technology, Electronic Engineering Polytechnic Institute of Surabaya, Indonesia
}

*Corresponding author:

E-mail:

syaifuddin.zuhri@upnjatim.ac.id

\begin{abstract}
Climate has a very decisive influence in influencing comfort conditions in space, one of which is its effect on lighting in the room. This lighting performance is greatly influenced by the performance of the openings that allow sunlight to enter the space so that the light intensity in the room can increase. There is a linear relationship between light intensity and aperture, so we need a way to optimize the performance of openings that can be controlled with a shade system or a device that can control the entry of sunlight into space. Active sunshade model or smart shading is one strategy to control incoming sunlight dynamically and to follow changes in light intensity that enters space. This actively adapting shading device is a shading device consisting of a vertical plane consisting of two panels that can move up and down according to the needs of room light intensity. This device is controlled by a control device that gets the light intensity data input from a sensor that is placed in the room to control the light intensity in the room. From the shading device that has been made, it is found that the performance of the device can adapt activities to the light intensity of space ranging from 100-200 lux in daytime conditions with an average panel opening of $12.81-14.42 \%$ of the window area.
\end{abstract}

Keywords: Shading strategy, smart shading, light intensity

\section{Introduction}

Daylighting into the room provides a multidimensional benefit that has been extensively reviewed in several literature. Providing sunlight through building openings allows a view outside the building, which simultaneously contributes to visual effects, psychological comfort, health, and productivity (Ander, 2017). In addition, there are two known natural lighting strategies namely passive and active natural lighting. Passive natural lighting strategy is a lighting strategy that is widely applied in conventional buildings. The development of sustainable architecture requires thoughts that are more practical and efficient and reduce dependence on excessive energy, so that the optimization of more effective sunlight control needs to be done, one of which is an active natural lighting strategy (Rissa, 2018; SNI, 2001).

Therefore, sosoran in Javanese architecture used to shading windows (openings) is one way to block the entry of sunlight into the building which is useful for reducing glare and heat that will disturb or increase room heat. So that the roof shading the openings can passively control the entry of hot sunshine at certain hours. So, a successful natural lighting design will consider using a sunshade device to reduce glare and excess heat in the building. (Imam et al., 2019). 
The use of conventional shading devices is still dominant in architectural applications in Indonesia and the use of technology and materials is still limited because it requires a broader crossdiscipline. This shade device is still a new research field in architectural research, so it still requires a lot of attention from researchers in developing future research (Zuhri \& Firdauzy, 2020). In addition, fixed external shading as passive devices strategy is widely recognized as an effective way to control heat gain and glare in buildings and reduce the energy of buildings and more costs efficiency under different climatic conditions. In comparison, the external shading systems are more effective than internal shading devices because it's more efficient to reduce the heat load on external buildings façade or spaces in humid tropical climates (Prowler, 2012). However, the shade device still has its limitations, and this system is unable to adapt to the varying conditions of the external conditions which are always changing and blocking the view outside the building.

From another research (Zuhri et al., 2010) it was explained that space openings greatly affect the quantity and quality of sunlight entering the room, likewise, if the openings do not have a shade system it will cause the intensity of light entering the room to also be uncontrolled. This research provides a solution by applying an automatic sun barrier system with a simple folding technique (Zuhri et al., 2020).

The active shading strategy is one of the alternatives to achieve a balance between adequate levels of natural lighting, providing sun protection, and energy balance, which allows residents to have the flexibility to control sun rays with shading devices according to their needs to reduce heat gain in the building. This active shading device is a system that tends to change its device in response to the conditions of sunlight entering from outside into space (Konstantoglou \& Tsangrassoulis, 2016).

The use of an active shade system reduces unwanted solar heat gain, improves the quality of sunlight, and provides a control for the user, as well as generating building energy and improving the performance of using natural ventilation. The use of technology in dynamic shade system applications is a new way in sun barrier system technology to reduce the intensity of sunlight entering the space. The use of technology will affect the performance of the device better and be adaptive according to the lighting needs in the room (Lee, 2004).

This paper is an attempt to increase the role of technology in a more adaptive application of shade devices in the world of architecture, while also influencing the development of more diverse building façade technologies in the future. As well as to understand the potentials needed in more depth to the problem so that designers can apply this strategy in solving lighting problems in space and its efficiency.

The shading device developed is called a dynamic shading device, this system can be used to control the conditions of the outside environment, in this case, the sunlight hitting the surface of the building so that the amount of sunlight entering the room can be controlled (Linn, C. 2014). The application of a dynamic shading system is an important step to increase the efficiency of sunlight in space. By using a dynamic shadowing system on the surface of the building, there will be a building surface or building façade that has the characteristics of a field that can move dynamically, in addition to its function to enter or control light in space (Das et al., 2017).

\section{Material and Methods}

This study uses two research approaches, namely qualitative and quantitative approaches. The qualitative method is used as a way to see the visual condition of the shading devices applied to the building and to monitor how its ability to move when changes in sunlight intensity are detected by light sensors placed in the room. Meanwhile, measuring the change in the area of the shading panel is used to measure the magnitude of the change in an area that occurs periodically when the light intensity changes in space so that characteristics and the relationship between changes in light intensity can be found and changes in the surface area of the opening when the shading device works. 
Data collection through direct measurements in the field is direct observation to be able to see and record in detail the changes in shade devices to changes in light intensity data received by the light sensor (Das et al., 2017). This direct field observation is to record, measure, and detect the visual changes of the shading device periodically from 8 o'clock to 16 o'clock, and then the data will be analyzed with the results of visual field measurements.

\section{Results and Discussion}

The application of the use of active shading devices is carried out in a building that has one window (opening) and the device is placed and attached to the front of the opening so that the device acts as a barrier to the entry of sunlight into the room. This device functions actively to control sunlight entering the room, meaning that the device can move dynamically following changes in the intensity of sunlight in the room. In this measurement, a limit with a value of 100 lux until 200 lux is used as the upper and lower limit so that the device can open or close as expected.

\section{Design prototype}

This sunshade device has the same concept as dynamic facades which are widely used to meet the energy needs of building envelopes, the folding shade system used is a shading device that is still new to be used in the world of architecture, especially as a facade building element. This device has a different typology of movements, such as translation and rotation, to suit its function to shade buildings. A new trend in shading device design is trying to replace the shading device system with a conventional mechanical system, and the development of this system uses an automatic actuator integrated with sensors that are responsible for controlling the device to move as needed.
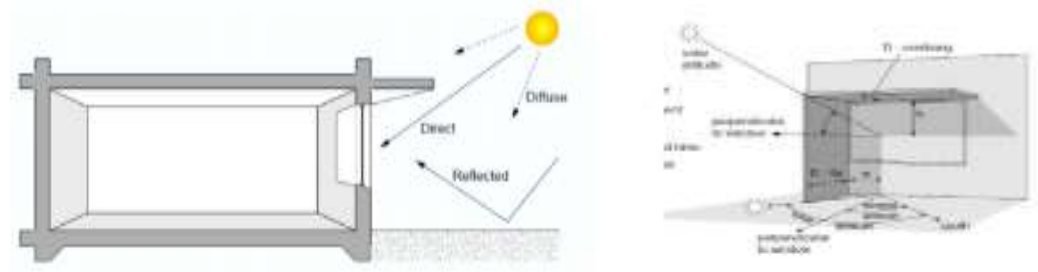

Figure 1. Sun rays mechanism and conventional strategy

Sunshade devices can block direct sunlight and reduce the effect of indirect illumination, namely the reflection of the sky and ground surface (Figure 1). The position of the sun determines the angle of incidence of sunlight on the glass surface (penetration). When the angle of incidence of the sun is equal to the angle of the shadow that forms a shading tool, direct sunlight can be moved effectively. Therefore, the position of the sun and the depth of the shade is a very important factor.

The geometric concept of active shade is influenced by the adaptive behavior of plants and the concept of the lotus which reacts to sunlight by moving upward-and-down linearly to close and open, and the triangular part covers the part of the pyramid. A geometric pattern has two parts: a dynamic and a static state created by integrating the shape of its moving linear plane. The dynamic section maximizes the difference between the extended and folded state receptive units to control daytime conditions when daytime lighting increases and affects indoor lighting (Figure 2). In this application, the proposed design uses a folding panel that can move dynamically on the axis of the stem. 


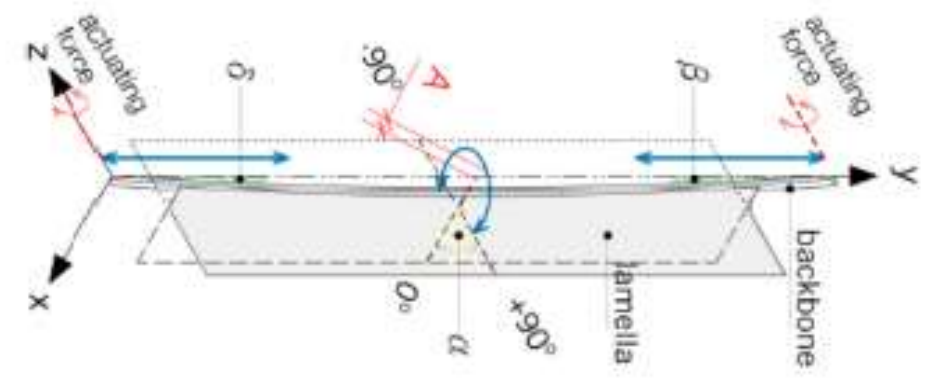

Figure 2. Kinetic shading mechanism

This sunshade device can be moved up and down by a hydraulic panel shading device or panel. The hydraulic dual panel system is equipped with a hydraulic system that regulates to opening and closing mechanism when the hydraulic drive motor works. These hydraulic shading panels are installed in front of openings or windows in spaces where natural lighting is required.
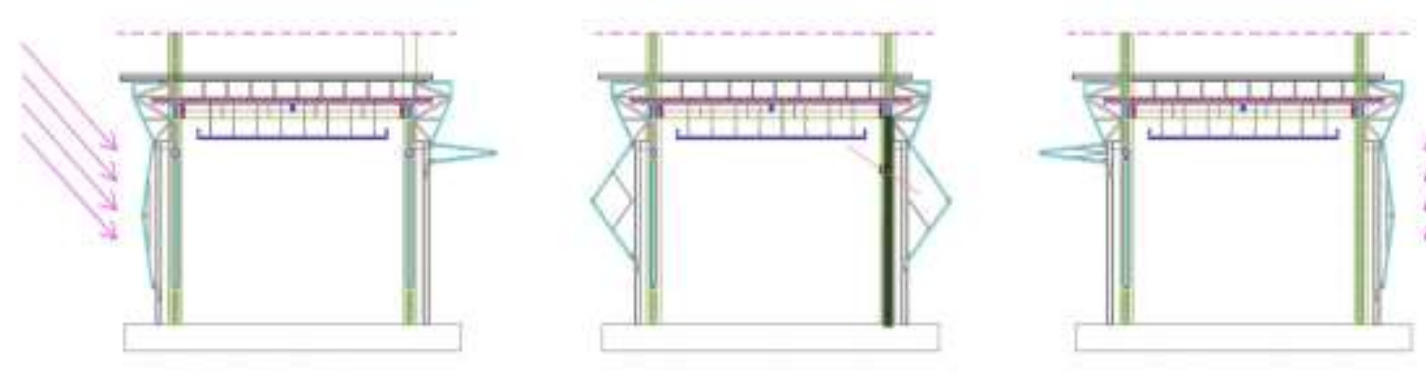

Figure 3. Shading position when sun position as vertical direction of the building

A shading device that is placed on the window opening (figure 4) which functions as an automatic shade can work to open and close according to the opening area. Position the shading panels that are placed on the east and west side of the building to get a perfect and optimal sunlight angle. The acquisition of sunlight in the morning and evening will provide variations in light intensity in different spaces so that the shade panel adaptation can be seen perfectly in each of these positions whether it can work properly or not.

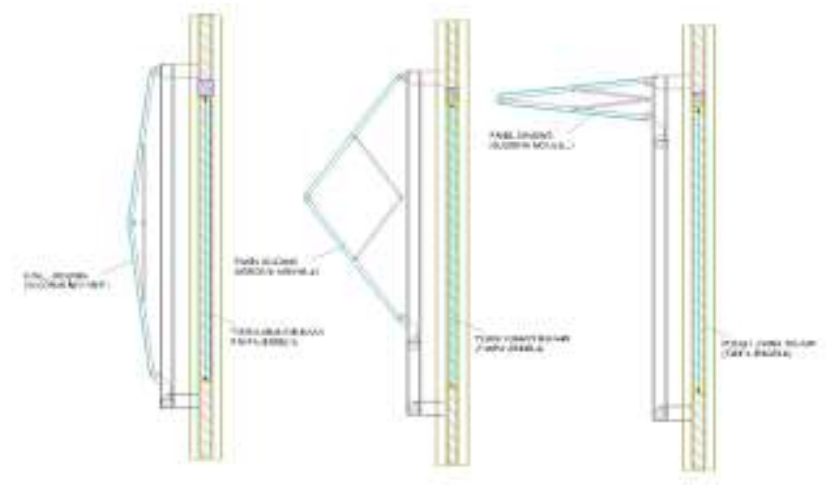

Figure 4. Closing and opening panel procedure 
The panel arrangement attached to the window opening consists of two planks connected by passive geometry rails and can rotate 180 degrees (Figure 4). For the panel to move up and down dynamically, the two upper ends of the panel are actively connected in the upper opening so that the panel can move dynamically but the panel remains in that position, while the bottom of the panel at both ends is mounted with a drive wheel that is placed on the rail mounted on the side of the opening so that the bottom of the panel can move dynamically up and down the rail.

\section{Automatic device control mechanism}

The shading panel drive system is based on the reception of sunlight received by a light sensor that is placed on the shading panel. In this study, a linear actuator electric drive system with a single axis type that moves on a one-sided vertical axis with control using an Arduino microcontroller. This control will regulate the light intensity change data that enters through the LDR sensor (Figure 5).

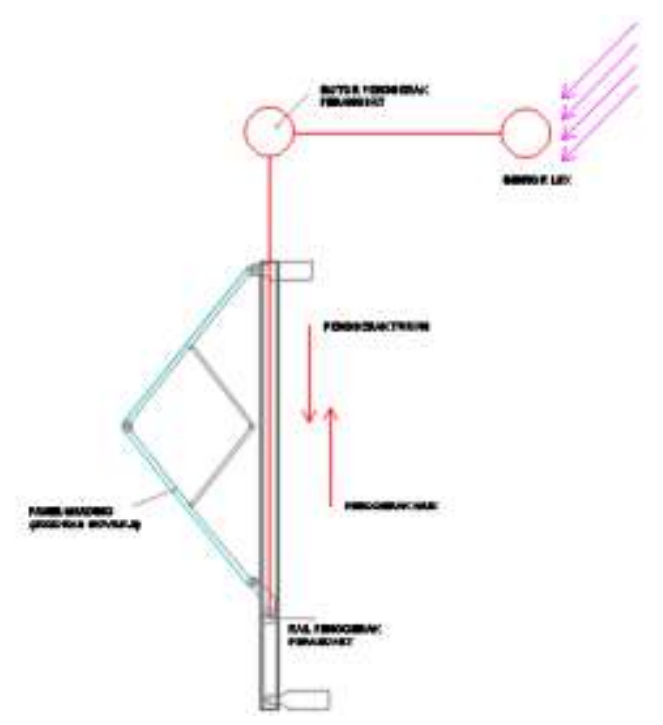

Figure 5. Shading device automation diagram

Sensors that work to capture sunlight entering the room will send this data to a series of tools called the Raspberry. This tool has a function as a single board mini computer that processes the data sent by the incoming light sensor, then the raspberry will process the data into commands aimed at the automatic motor to work to move the motor wheel to rotate. With the rotation of the motor wheel, the panel will be lifted automatically, and the movement depends on whether the sunlight received by the sensor is following the standard needs of light intensity in space. If the light intensity in the room is still too low quality, the raspberry will raise the panel to the optimal limit needed.

The use of a light sensor using the LDR system is a sensor whose resistance value works according to the amount of light, this tool is connected to a raspberry microcontroller which will accommodate the data provided by the sensor to control the rotation of the linear actuator connected to the shading panel. This actuator has a function to be able to move the panel dynamically so that it can be seen how the panel responds to the movement of sunlight which will be tested in the time range between 6:00 and 18:00.

\section{Automatic device mechanism}

The field of the imaging device consists of two device fins that can move up and down based on changes in the intensity of light hitting the sensor. For the device to move open and close, an 
electric linear micro controller actuator is installed. The operation of the shading device drive system using the rail connector is described based on the diagram below (Figure 5).

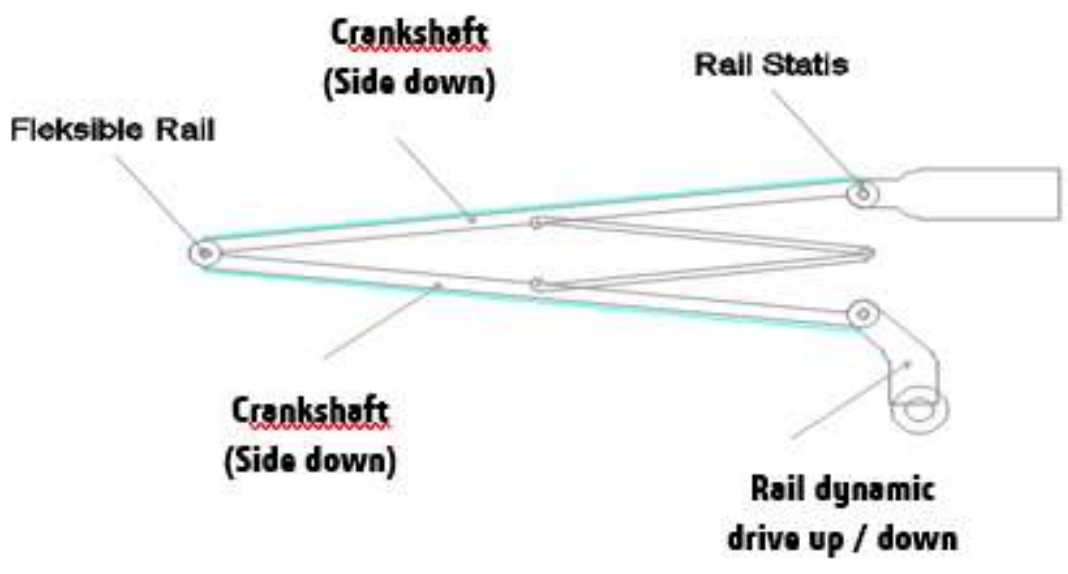

Figure 5. Details of shading device

Sunlight shading devices are used as an automatic barrier to control the entry of sunlight into space. This device has a component for controlling the movement of the panel which includes a pulley for moving the panel shade device which is controlled by the raspberry system. The movement of this panel moves geometrically according to the position where the panel is placed (figure 5). The panels are divided into 2 areas A and B which are connected by hinges so that the two panels can move freely according to their axes so that the panels do not come out of the opening plane, the two panels are installed with rails attached to both sides of the opening. And the movement of the panel's shading can be moved in one direction along the axis of the rail with a maximum turning radius of 90 degrees.

The movement of the panel is likened to a simple scissor that moves on its axis and to be able to move constantly on that axis, the panel is connected to an automatic pulley system that will lift or lower the panel so that the panel can slide up and down linearly. A simple pulley that is used to lift and lower the panel based on the need or according to the size of the light intensity in the room, or simple motor-controlled drive wheels to control the panel to move up-and-down motion. For controlling the quality of the lux intensity of the room carried out by a flux sensor that is placed in the room.

\section{Conclusion}

The panel of the sunlight device attached to the opening serves to control the entry of sunlight into space. In the experimental results, the tool can work by responding to changes in the intensity of sunlight captured by the sensor so that the panel moves to open and close according to the size of the received sunlight intensity. The flux sensor setting is set with a range of 100-200 lux to determine the response of the device panel to this change in intensity, from the experimental results it can be seen that the panel can actively open and close.

From the experimental results, it can be seen that the ability of the device to open and close reaches $13.38 \%$ of the installed opening area. So, it can be explained that the ability of the panel to respond to open and close can work well, because of the outside environment with very high sunlight intensity. The use of a lifting pulley so that the device panel can be opened and closed also works well even though the use of the pulley is still too small while the device panel is still too heavy so that the movement is too slow. 


\section{Acknowledgment}

The author is very grateful for the completion of this article. This article is a series of research activities that have been carried out by the author and the team through the acceptance of a research proposal with an independent research scheme at the "Veteran" East Java National Development University in 2020. Or the research road map, which is a series of research of architecture environment are architecture, building, and technology.

And this research is a research phase developed by the author in the field of architecture and building technology. The author understands that many contributions have been made by friends in the environment and architecture study program in developing this article and its publication in several national and international journals. On this occasion, the author would like to express his deep appreciation and gratitude for your support and participation.

\section{References}

Ander, G. D. (2017). Daylighting. Whole design building guide, U.S. Department of Energy.

Das, S. K., Verma, D., Nema, S., \&Nema, R. K. (2017). Shading mitigation techniques: State of the art in photovoltaic applications. Renew. Sustain. Energy.

Imam, M. N., Dedes N. G., \& Khotijah, L. (2019). Inovasi perancangan peneduh bangunan kantor dengan tipologi bangunan bertingkat Jakarta. Prosiding Seminar 2, Peningkatan Kualitas Hidup \& Peradaban Dengan Konteks ilmu pengetahuan teknologi seni, September 2019.

Konstantoglou, M., \& Tsangrassoulis. (2016). A dynamic operation of day lighting and shading systems: A literature review. Renewable. Sustainable. Energy Rev. 2016.

Lee, E. S., Selkowitz, S. E., Hughes, G. D., \& Thurm, D. A. (2004). Market transformation opportunities for emerging dynamic facade and dimmable lighting control systems. Pacific Grove, CA, USA: Lawrence Berkeley National Laboratory.

Linn, C. (2014). Kinetic Architecture: Design for Active Envelopes. Victoria, Australia: Images Publishing.

Prowler, M. J. (2012). Sun control \& shading device system. 23 April 2012.

Rissa D. U. (2018). Evaluasi sistem penerangan alami ruang kontrol utama gedung Irradiator Gama M.P Batan. Jurnal Prima, 15(2), 2018.

SNI - Standar Nasional Indonesia (03-2396-2001). (2001). Tata Cara Perancangan Sistem Pencahayaan Alami Gedung, Badan Standarisasi Nasional.

Zuhri, S., Imam G., \& Heru S. (2010). Optimization of Space Utilization in Penjaringan Sari Flats Surabaya. International Seminar of Research Month (ISRM): Science \& Technology in Publication, Implementation \& Commercalization, at UPN East Java, Surabaya.

Zuhri, S., \& Firdauzy, K. (2020). Optimizing smart shading system in the unit residential housing in Surabaya. IJISET - International Journal of Innovative Science, Engineering \& Technology, 7(10), 1-10. 